\title{
THE TRIBOLOGICAL PERFORMANCES OF A NiCrBSi - TiC LASER-CLAD COMPOSITE COATING UNDER ABRASION AND SLIDING FRICTION
}

\author{
A. V. Makarov ${ }^{1,2}$, N. N. Soboleva ${ }^{1}$, I. Yu. Malygina ${ }^{1}$, A. L. Osintseva ${ }^{1}$ \\ ${ }^{1}$ Institute of Engineering Science, Ural Branch of the Russian Academy of Sciences, 34 Komsomolskaya st., \\ Ekaterinburg, Russian Federation; \\ ${ }^{2}$ Institute of Metal Physics, Ural Branch of the Russian Academy of Sciences, 18 Kovalevskoy St., Ekaterinburg, \\ Russian Federation \\ *Corresponding author. E-mail: soboleva@imach.uran.ru; address for correspondence: 34 Komsomolskaya st., \\ Ekaterinburg, Russian Federation. Tel.: +7 (343) 375-35-78; fax: 374-53-30
}

A comparative analysis of the structure, phase composition, microhardness, tribological performances (wear intensity, friction coefficient, specific wearing work) and wear mechanisms in fixed abrasive tests (abrasives with different hardness, namely, corundum A12O3 with HV 2000 and silicon carbide with $\sim$ HV 3000) and under dry sliding friction against die steel has been carried out for a NiCrBSi coating and a NiCrBSi-TiC (with $25 \%$ wt. TiC addition) composite coating obtained on the surface of steel by gas powder laser cladding. The high-strength frame of coarse titanium carbide particles in the composite coating structure has a significant positive impact on resistance to abrasive wear and sliding friction, and the effectiveness greatly depends on the contact loading conditions and wear mechanism realized.

Keywords: laser cladding, NiCrBSi - TiC composite coating, structure, microhardness, abrasive wear, sliding friction.

DOI: $10.17804 / 2410-9908.2015 .3 .083-097$

\section{References}

1. Kurganova Yu.A., Kolmakov A.G. Konstruktsionnye metallomatrichnye kompozitsionnye materialy: uchebnoe posobie [Constructional metal matrix composite materials: educational book]. Moscow, MGTU im. N. E. Baumana Publ., 2015. 141 p. (In Russian).

2. Kurganova Yu.A. Development prospects of commercial metal matrix composite materials. Servis v Rossii i za rubezhom, 2012, vol. 30, no. 3, pp. 235-240. (In Russian).

3. Yan H., Zhang P., Yu Zh., Lu Q., Yang Sh., Li Ch. Microstructure and tribological properties of laser-clad $\mathrm{Ni}-\mathrm{Cr} / \mathrm{TiB}_{2}$ composite coatings on copper with the addition of $\mathrm{CaF}_{2}$. Surface and Coatings Technology, 2012, vol. 206, pp. 4046-4053.

4. Nurminen J., Näkki J., Vuoristo P. Microstructure and properties of hard and wear resistant MMC coatings deposited by laser cladding. Int. Journal of Refractory Metals and Hard Materials, 2009, vol. 27, pp. 472-478.

5. Anandkumar R., Almeida A., Vilar R. Wear behavior of Al-12Si/ $\mathrm{TiB}_{2}$ coatings produced by laser cladding. Surface and Coatings Technology, 2011, vol. 205, pp. 3824-3832.

6. Tobar M.J., Álvarez C., Amado J.M., Rodríguez G., Yánez A. Morphology and characterization of laser clad composite NiCrBSi-WC coatings on stainless steel. Surface and Coatings Technology, 2006, vol. 200, pp. 6313-6317.

7. Weng F., Chen $\mathrm{Ch}$., $\mathrm{Yu} \mathrm{H}$. Research status of laser cladding on titanium and its alloys: A review. Materials and Design, 2014, vol. 58, pp. 412-425.

8. Makarov A.V., Savrai R.A., Osintseva A.L., Malygina I.Yu. The influence of the chemical composition on the tribological performances of $\mathrm{Cr}-\mathrm{Ni}$ coatings obtained by gas powder laser cladding. Izvestiya Chelyabinskogo nauchnogo tsentra, 2009, no. 2 (44), pp. 28-33. (In Russian). 
9. Soboleva N.N., Malygina I.Yu., Osintseva A.L., Pozdejeva N.A. The influence of the microstructure and phase composition on tribological performances of NiCrBSi coatings. Izvestiya Samarskogo nauchnogo tsentra Rossiyskoy Akademii Nauk, 2011, vol. 13, no. 4 (3), pp. 869-873. (In Russian).

10. Cai B., Tan Y.-F., He L., Tan H., Gao L. Tribological properties of TiC particles reinforced Ni-based alloy composite coatings. Transactions of Nonferrous Metals Society of China, 2013, vol. 13, pp. 1681-1688.

11. Yang J., Liu F., Miao X., Yang F. Influence of laser cladding process on the magnetic properties of WC-FeNiCr metal-matrix composite coatings. Journal of Materials Processing Technology, 2012, vol. 212, pp. 1862-1868.

12. Niranatlumpong P., Koiprasert H. Phase transformation of NiCrBSi-WC and NiBSi-WC arc sprayed coatings. Surface and Coatings Technology, 2011, vol. 206, pp. 440-445.

13. Guo Ch., Chen J., Zhou J., Zhao J., Wang L., Yu Y., Zhou H. Effects of WC-Ni content on microstructure and wear resistance of laser cladding Ni-based alloys coating. Surface and Coatings Technology, 2012, vol. 206, pp. 2064-2071.

14. Liyanage T., Fisher G., Gerlich A.P. Microstructures and abrasive wear performance of PTAW deposited Ni-WC overlays using different Ni-alloy chemistries. Wear, 2012, vol. 274-275, pp. 345-354.

15. Si S.-H., Yuan X.-M., Liu Y.-L., He Y.-Z., Keesam Sh. Effect of Laser Power on Microstructure and Wear Resistance of $\mathrm{WC}_{\mathrm{P}} / \mathrm{Ni}$ Cermet Coating. Journal of Iron and Steel Research, International, 2006, vol. 13, Iss. 3, pp. 74-78.

16. Mendez P.F., Barnes N., Bell K., Borle S.D., Gajapathi S.S., Guest S.D., Izadi H., Gol A.K., Wood G. Welding processes for wear resistant overlays. Journal of Manufacturing Processes, 2014, vol. 16, pp. 4-25.

17. Zikin A., Antonov M., Hussainova I., Katona L., Gavrilovic' A. High temperature wear of cermet particle reinforced NiCrBSi hardfacings. Tribology International, 2013, vol. 98, pp. 45-55.

18. Li Q., Song G.M., Zhang Y.Z., Lei T.C., Chen W.Z.. Microstructure and dry sliding wear behavior of laser clad Ni-based alloy coating with the addition of SiC. Wear, 2003, vol. 254, iss. $3-4$, pp. 222-229.

19. Chao M.-J., Wang W.-L., Liang E.-J., Ouyang D. Microstructure and wear resistance of TaC reinforced Ni-based coating by laser cladding. Surface and Coatings Technology, 2008, vol. 202, pp. 1918-1922.

20. Zikin A., Badisch E., Hussainova I., Tomastik C., Danninger H. Characterisation of TiCNiMo reinforced Ni-based hardfacing. Surface and Coatings Technology, 2013, vol. 236, pp. 36-44.

21. Wang X.H., Zhang M., Liu X.M., Qu S.Y., Zou Z.D. Microstructure and wear properties of $\mathrm{TiC} / \mathrm{FeCrBSi}$ surface composite coating prepared by laser cladding. Surface and Coatings Technology, 2008, vol. 202, pp. 3600-3606.

22. Makarov A.V., Soboleva N.N., Malygina I.Yu., Osintseva A.L. The formation of a NiCrBSi-TiC composite coating with increased abrasive wear resistance by gas powder laser cladding. Uprochnyayushchie tekhnologii i pokrytiya, 2013, no. 11 (107), pp. 38-44. (In Russian).

23. Sun R.L., Lei Y.W., Niu W. Laser clad TiC reinforced NiCrBSi composite coatings on Ti-6Al-4V alloy using a $\mathrm{CW} \mathrm{CO}_{2}$ laser. Surface and Coatings Technology, 2009, vol. 203, pp. 1395-1399.

24. Lei Y., Sun R., Tang Y., Niu W. Numerical simulation of temperature distribution and TiC growth kinetics for high power laser clad TiC/NiCrBSiC composite coatings. Optics and Laser Technology, 2012, vol. 44, pp. 1141-1147. 
25. Lei Y., Sun R., Lei J., Tang Y., Niu W. A new theoretical model for high power laser clad TiC/NiCrBSiC composite coatings on Ti6Al4V alloys. Optics and Lasers in Engineering, 2010, vol. 48, pp. 899-905.

26. Duraiselvam M., Galun R., Wesling V., Mordike B.L., Reiter R., Oligmüller J., Buvanashekaran G. Cavitation erosion resistance of Ti6Al4V laser alloyed with TiC-reinforced dual phase intermetallic matrix composites. Materials Science and Engineering A, 2007, vol. 454-455, pp. 63-68.

27. Tan Y.-F., He L., Wang X.-L., Hong X., Wang W.-G. Tribological properties and wear prediction model of TiC particles reinforced Ni-base alloy composite coatings. Transactions of Nonferrous Metals Society of China, 2014, vol. 24, pp. 2566-2573.

28. Cai B., Tan Y.-F., Tu Y.-Q., Wang X.-L., Tan H. Tribological properties of Ni-base alloy composite coating modified by both graphite and TiC particles. Transactions of Nonferrous Metals Society of China, 2011, vol. 21, pp. 2426-2432.

29. Dawei Z., Li T., Lei T.C. Laser cladding of $\mathrm{Ni}-\mathrm{Cr}_{3} \mathrm{C}_{2} /(\mathrm{Ni}+\mathrm{Cr})$ composite coating. Surface and Coatings Technology, 1988, vol. 110, pp. 81-85.

30. Makarov A.V., Gorkunov E.S., Malygina I.Yu., Kogan L.Kh., Savrai R.A., Osintseva A.L. Eddy-current testing of the hardness, wear resistance and thickness of coatings prepared by gaspowder laser cladding. Russian Journal of Nondestructive Testing, 2009, vol. 45, iss. 11, pp 797-805.

31. Makarov A.V., Pozdejeva N.A., Savrai R.A., Yurovskikh A.S., Malygina I.Yu. Improvement of wear resistance of quenched structural steel by nanostructuring frictional treatment. Journal of Friction and Wear, 2012, vol. 33, no. 6, pp. 433-442.

32. Khrushchov M.M., Babichev M.A. Abrazivnoye iznashivanie [Abrasive wear]. Moscow, Nauka Publ., 1970. 252 p. (In Russian).

33. Kragelsky I.V., Dobychin M.N., Kombalov V.S. Osnovy raschetov na trenie i iznos [A basis for friction and wear calculation]. Moscow, Mashinostroenie Publ., 1977. 526 p. (In Russian).

34. Kragelsky I.V. Trenie i iznos [Friction and wear]. Moscow, Mashinostroenie Publ., 1968, 480 p. (In Russian).

35. Golego N.L. Skhvatyvanie v mashinakh i metody ego ustraneniya [Seizure in machines and methods for its elimination]. Kiev, Tekhnika Publ., 1966, 231 p. (In Russian).

36. Nosovsky I.G. Vliyanie gazovoy sredy na iznos metallov [The effect of a gaseous medium on metal wear]. Kiev, Tekhnika Publ., 1968, 181 p. (In Russian).

37. Kostatsky B.I., Nosovsky I.G., Karaulov A.K. et al. Poverkhnostnaya prochnost materialov pri trenii [Surface strength of materials during friction]. Kiev, Tekhnika Publ., 1976. 296 p. (In Russian). 
Подана в журнал: 05.06.2015

УДК 621.791.92:620.178

DOI: $10.17804 / 2410-9908.2015 .3 .083-097$

\title{
ТРИБОЛОГИЧЕСКИЕ СВОЙСТВА КОМПОЗИЦИОННОГО ПОКРЫТИЯ NiCrBSi - TiC, ПОЛУЧЕННОГО ЛАЗЕРНОЙ НАПЛАВКОЙ, ПРИ АБРАЗИВНОМ ВОЗДЕЙСТВИИ И ТРЕНИИ СКОЛЬЖЕНИЯ
}

\author{
А. В. Макаров ${ }^{1,2}$, Н. Н. Соболева ${ }^{1}$, И. Ю. Малыгина ${ }^{1}$, А. Л. Осинцева ${ }^{1}$ \\ ${ }^{I}$ Федеральное государственное бюджетное учреждение науки Институт матиноведения Уральского \\ отделения Российской академии наук, ул. Комсомольская, 34, Екатеринбург, Российская Федерация \\ ${ }^{2}$ Федеральное государственное бюджетное учреждение науки Институт физики металлов Уральского \\ отделения Российской академии наук, ул. С. Ковалевской, 18, Екатеринбург, Российская Федерация \\ *Ответственный автор. Электронная почта: soboleva@imach.uran.ru; адрес для переписки: ул. Комсомольская, \\ 34, Екатеринбург, Российская Федерация. Телефон: +7 (343) 375-35-78; факс: 374-53-30
}

Проведен сравнительный анализ структурно-фазового состояния, микротвердости, трибологических свойств (интенсивность изнашивания, коэффициент трения, удельная работа изнашивания) и механизмов изнашивания при испытаниях по закрепленному абразиву различной твердости (корунд $\mathrm{Al}_{2} \mathrm{O}_{3}$ твердостью HV 2000, карбид кремния $\mathrm{SiC}$ твердостью $\sim$ HV 3000), а также в условиях трения скольжения без смазки по стали Х12М базового покрытия NiCrBSi и композиционного покрытия $\mathrm{NiCrBSi}-\mathrm{TiC}$ (с добавкой 25\% масс. TiC), полученных на поверхности пластины из стали Ст3 методом газопорошковой лазерной наплавки. Установлено, что сформированный в структуре композиционного покрытия высокопрочный каркас из крупных частиц карбида титана ТiC оказывает на сопротивление изнашиванию при абразивном воздействии и трении скольжения существенное положительное влияние, эффективность которого в сильной степени зависит от условий контактного нагружения и реализующихся механизмов изнашивания.

Ключевые слова: лазерная наплавка, композищионное покрытие $\mathrm{NiCrBSi}-\mathrm{TiC}$, структура, микротвердость, абразивное изнашивание, трение скольжения.

\section{1. Введение}

Повышение конструкционной прочности, надежности и долговечности деталей механизмов и машин - одна из первоочередных задач современного машиностроения [1]. Основной причиной выхода из строя большинства механизмов и машин является износ подвижных сопряжений и рабочих органов под влиянием сил трения. Однако не всегда возможно добиться требуемого уровня свойств за счет применения традиционных металлических материалов в основном из-за их несоответствия новым повышенным требованиям к прочности, жесткости, износостойкости [2].

В металломатричных композиционных материалах (МКМ), состоящих из относительно мягкой матрицы и твердых упрочняющих частиц, сочетаются достоинства конструкционных металлических материалов и наполнителя, поэтому МКМ присущи высокие значения прочностных характеристик, модулей упругости, вязкости разрушения, сохранение стабильности механических и эксплуатационных свойств в широких температурных пределах, малая чувствительность к поверхностным дефектам [1].

В последние годы большой интерес в литературе в качестве метода нанесения металломатричных покрытий вызывает лазерная наплавка [3-5]. В этом процессе тонкий поверхностный слой основного металла оплавляется лазерным лучом совместно с присадочным материалом [6]. Создание металломатричных композиционных материалов осуществляется одновременной подачей металлического порошка и порошка твердых частиц, обычно карби- 
дов, в зону расплавленного металла и может быть реализовано при довольно высоком различии температур плавления матрицы и карбидов [4]. В результате получаются плотные покрытия, обычно толщиной 0,5-3,0 мм, характеризующиеся хорошим металлургическим сцеплением с основой, при этом свойства объема металла остаются практически неизменными $[4,7]$.

Сплавы NiCrBSi широко используются в качестве материала матрицы износостойких композиционных покрытий благодаря их высокой стойкости к различным видам изнашивания и воздействию коррозии [8-10]. Они имеют относительно низкую точку плавления и могут выполнять роль пластичной связки для упрочняющих фаз [11]. В качестве упрочняющих фаз в покрытиях на основе $\mathrm{NiCrBSi} \mathrm{используются} \mathrm{добавки} \mathrm{карбидов} \mathrm{WC} / \mathrm{W}_{2} \mathrm{C}$ [12-16], $\mathrm{Cr}_{3} \mathrm{C}_{2}$ [17], $\mathrm{SiC}$ [18], ТaC [19], борида $\mathrm{TiB}_{2}$ [3] и других соединений. Карбид титана (TiC) также может быть успешно использован для формирования металломатричных композиционных покрытий благодаря наличию у него высоких уровней твердости, модуля упругости, температуры плавления и хорошей стойкости к окислению [10, 20-22].

Многие из изученных в литературе покрытий системы $\mathrm{NiCrBSi}-\mathrm{TiC}$ были нанесены на подложку из титанового сплава [23-26], в работе [27] в качестве основы использовался алюминиевый сплав. В работах $[10,28]$ получали композиционные покрытия такого типа на поверхности углеродистой стали 45, однако применяли при этом метод плазменного напыления. Введение в состав хромоникелевого покрытия значительных количеств карбида титана может сопровождаться охрупчиванием покрытия в определенных условиях контактного нагружения, в частности при сухом трении скольжения [10]. При абразивном воздействии в зависимости от соотношения твердости карбида титана и абразивных частиц можно ожидать различной эффективности использования добавок высокопрочных частиц ТіС для повышения износостойкости покрытий.

Поэтому важным как с научной, так и с практической точек зрения представляется изучение структуры и поведения в различных условиях изнашивания композиционного ТiC $\mathrm{NiCrBSi} \mathrm{покрытия,} \mathrm{сформированного} \mathrm{на} \mathrm{поверхности} \mathrm{стали} \mathrm{лазерной} \mathrm{наплавкой.}$

Цель настоящей работы заключается в проведении сравнительного анализа структурно-фазового состояния, микротвердости, трибологических свойств и механизмов изнашивания при испытаниях по закрепленному абразиву различной твердости (корунд, карбид кремния), а также в условиях трения скольжения без смазки NiCrBSi покрытия и композиционного покрытия $\mathrm{NiCrBSi}$ - TiC (с добавкой 25 \% масс. TiC), полученных на поверхности стальной пластины методом газопорошковой лазерной наплавки.

\section{2. Материал и методика эксперимента}

Газопорошковая лазерная наплавка проводилась $\mathrm{CO}_{2}$-лазером непрерывного действия при мощности излучения 1,4-1,6 кВт, скорости 160 мм/мин, расходе порошка 2,9-3,8 г/мин, размере лазерного пятна на стальной поверхности $6 \times 1,5$ мм. NiCrBSi порошок ПГ-СР2 $(0,48 \% \mathrm{C} ; 14,8 \% \mathrm{Cr} ; 2,6 \% \mathrm{Fe} ; 2,9 \% \mathrm{Si} ; 2,1 \% \mathrm{~B}$; остальное - Ni) гранулометрического состава до 160 мкм и порошковая смесь, полученная перемешиванием двух порошков (порошка ПГСР2 и порошка ТіС гранулометрического состава 50-100 мкм в количестве 25 масс. \%), транспортировались в зону наплавки инертным газом - аргоном - при давлении 0,5 атм. Наплавка покрытия на пластину из стали Ст3 осуществлялась в два прохода для уменьшения поверхностных напряжений. Для устранения волнистости наплавленная поверхность подвергалась шлифованию с интенсивным охлаждением.

Структуру, химический и фазовый состав покрытий изучали с применением сканирующего электронного микроскопа VEGA II XMU, оборудованного волнодисперсионным (Inca Wave 700) и энергодисперсионным (INCA Energy 450 XT) микроанализаторами, и рентгеновского дифрактометра SHIMADZU XRD-7000. Микротвердость измеряли на микротвердомере Leica VMHT AUTO при нагрузке 0,98 Н на индентор Виккерса, время нагружения 15

Makarov A. V. et al. / The tribological performances of a NiCrBSi - TiC laser-clad composite coating under abrasion and sliding friction. 
с. Погрешность измерения микротвердости определяли с доверительной вероятностью $\mathrm{p}=$ 0,95 .

Испытания на абразивное изнашивание проводили при скольжении торцевых поверхностей (7×7 мм) наплавленных образцов по закрепленным абразиву двух видов (корунду $\mathrm{Al}_{2} \mathrm{O}_{3}$ зернистостью 160 мкм и твердостью $\sim \mathrm{HV} 2000$ и карбиду кремния $\mathrm{SiC}$ зернистостью 160 мкм и твердостью HV 3000) со средней скоростью 0,175 м/с, при нагрузке 49 Н, поперечном смещении образца за один двойной ход 1,2 мм, пути трения 18 м. Испытания в условиях трения скольжения проводили при возвратно-поступательном скольжении торцевой поверхности образца по пластине из стали X12M (62...64 НRСэ) на воздухе без смазки, при нагрузке $294 \mathrm{H}$ средней скорости скольжения 0,07 м/с, длине рабочего хода 40 мм и пути трения 160 м. Коэффициент трения определяли как отношение силы трения к нормальной нагрузке $\mathrm{f}=\mathrm{F} / \mathrm{N}$, где $\mathrm{F}$ - сила трения, $\mathrm{H}$; $\mathrm{N}$ - нормальная нагрузка, Н. Интенсивность изнашивания рассчитывали по формуле $\mathrm{Ih}=\mathrm{Q} /(\rho \mathrm{SL})$, где $\mathrm{Q}$ - потери массы образца, г; $\rho$ - плотность материала, г/ $\mathrm{cm}^{3} ; \mathrm{S}$ - геометрическая площадь контакта, $\mathrm{cm}^{2} ; \mathrm{L}$ - путь трения, см. Для расчета удельной работы изнашивания применяли формулу $\mathrm{W}=\mathrm{fNL} \rho / \mathrm{Q}$, где $\mathrm{f}-$ коэффициент трения; L - путь трения, м.

Поверхности покрытий после абразивного изнашивания и испытаний на трение скольжения изучали с помощью сканирующего электронного микроскопа VEGA II XMU.

\section{3. Экспериментальные результаты и их обсуждение}

В результате двухслойной газопорошковой лазерной наплавки на поверхности стали были сформированы покрытия, толщина которых после механического шлифования составляла $0,7-0,9$ мм.

Согласно данным сканирующей электронной микроскопии, микрорентгеноспектрального и рентгеноструктурного методов анализа (рис. 1 и 2), основу покрытий обоих типов представляет $\gamma$-твердый раствор на основе никеля $(\gamma$-Ni) и эвтектика, состоящая из $\gamma$-Ni и боридной фазы $\mathrm{Ni}_{3} \mathrm{~B}$. Указанная эвтектика формируется в результате взаимодействия между В и Ni в условиях быстрого нагрева и охлаждения во время лазерной обработки [29].
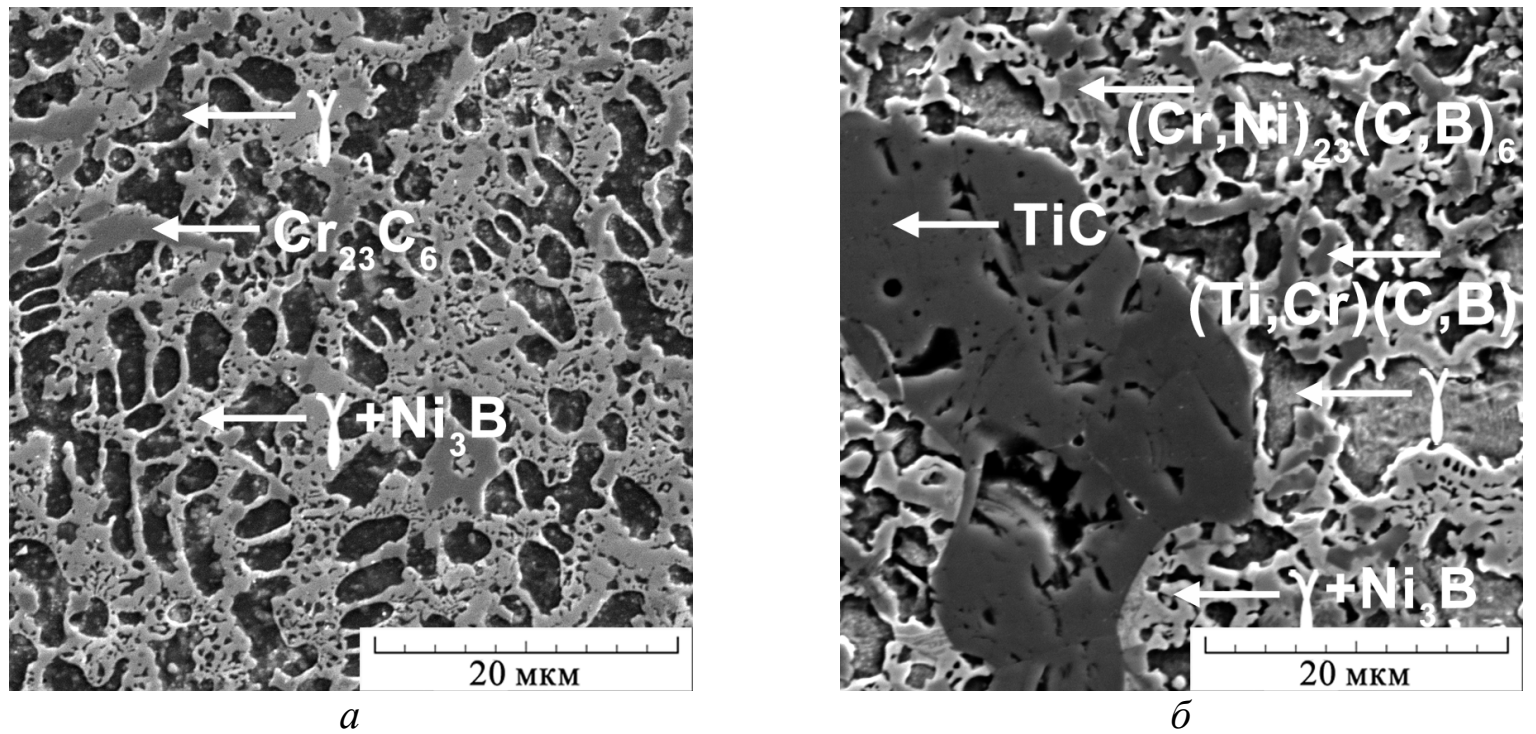

Рис. 1. Структура и фазовый состав покрытий NiCrBSi $(a)$ и $\mathrm{NiCrBSi}-\mathrm{TiC}(б)$

Упрочняющей фазой покрытия ПГ-СР2 является карбид $\mathrm{Cr}_{23} \mathrm{C}_{6}$ (рис. 1 a и $2 a$ ). Структура покрытия ПГ-СР2 характеризуется достаточно равномерным распределением структурных составляющих (рис. $3 a$ ) по всей толщине покрытия [30]. 
open-2eceess journal

При добавлении 25 масс. \% ТiC в состав порошка ПГ-СР2 при наплавке формируется металломатричное композиционное покрытие типа NiCrBSi - TiC. На рентгеновской дифрактограмме данного покрытия видны дополнительные пики (см. рис. 2 б), свидетельствующие о формировании новых фаз по сравнению с фазовым составом NiCrBSi покрытия (см. pис. 2 a). В покрытии $\mathrm{NiCrBSi}$ - TiC присутствуют крупные включения первичных карбидов титана $\mathrm{TiC}$, которые не полностью растворились при наплавке вследствие высокой температуры плавления кабида $\mathrm{TiC}\left(3140{ }^{\circ} \mathrm{C}\right)$ и тем самым позволили сформировать композиционное покрытие (см. рис. 1 б и 3 б). Наряду с указанными крупными карбидами ТіС образуются также дисперсные карбобориды $(\mathrm{Cr}, \mathrm{Ni})_{23}(\mathrm{C}, \mathrm{B})_{6}$ и $(\mathrm{Ti}, \mathrm{Cr})(\mathrm{C}, \mathrm{B})($ см. рис. 1 б и 2 б), являющиеся результатом частичного растворения частиц карбида титана в процессе лазерной наплавки [22].

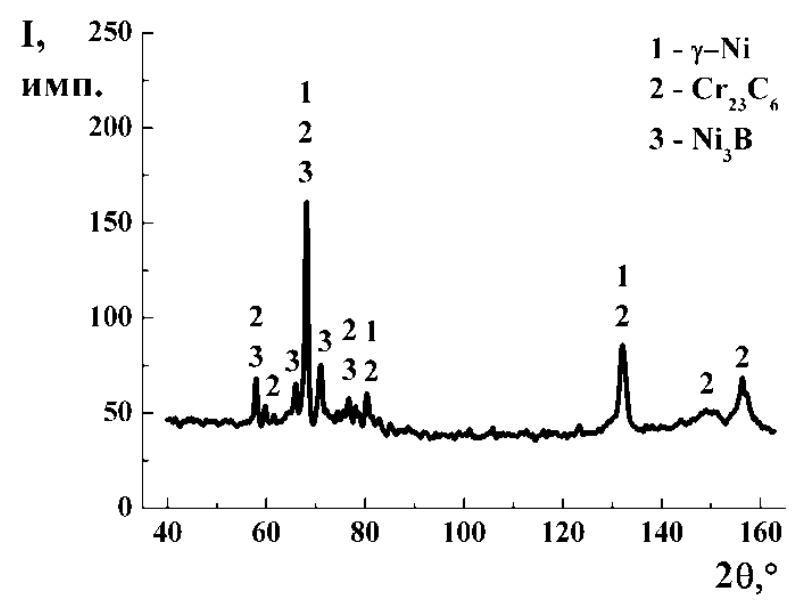

$a$

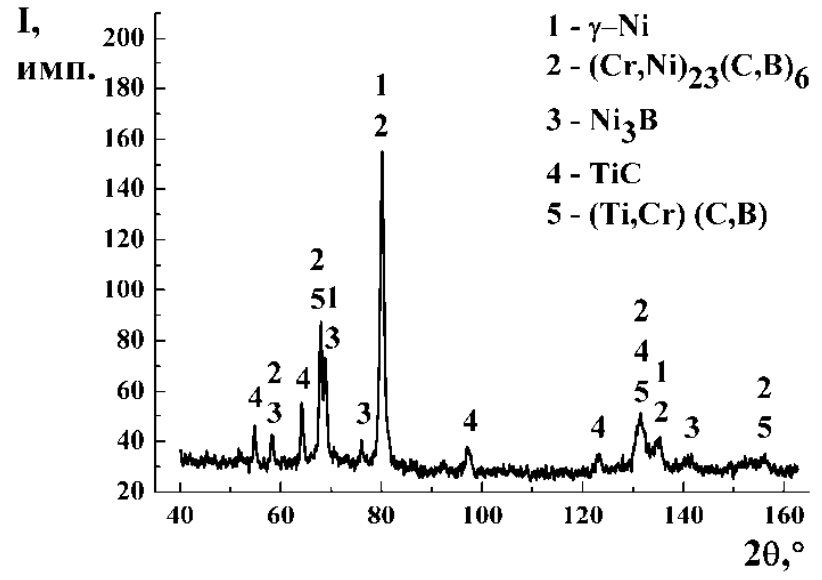

$\sigma$

Рис. 2. Рентгеновские дифрактограммы покрытий $\mathrm{NiCrBSi}(a)$ и $\mathrm{NiCrBSi}-\mathrm{TiC}$ (б)

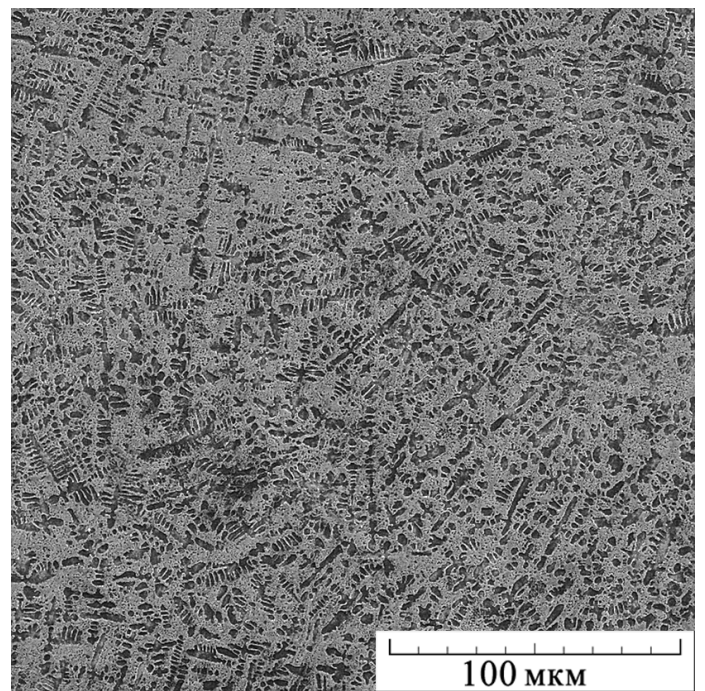

$a$

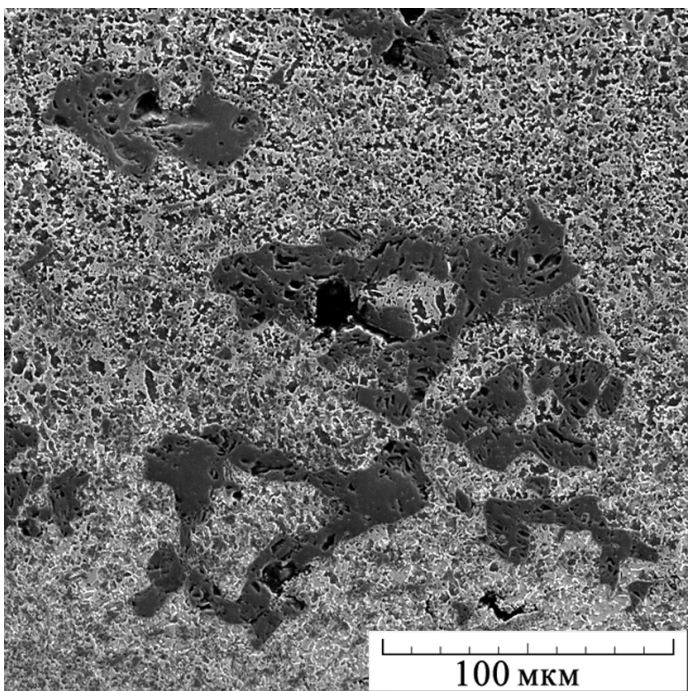

$\sigma$

Рис. 3. Структура покрытий $\mathrm{NiCrBSi}(a)$ и $\mathrm{NiCrBSi}-\mathrm{TiC}$ (б)

Результаты измерения микротвердости рассматриваемых покрытий представлены на pис. 4 и в табл. 1. Средняя микротвердость покрытия ПГ-СР2 составляет HV $520 \pm 10$. При добавке 25 масс.\% ТіС в состав порошка ПГ-СР2 достигается эффективное упрочнение формируемого композиционного покрытия до среднего уровня HV $770 \pm 60$ вследствие наличия в структуре композиционного покрытия высокопрочных (твердостью более HV 2000) частиц карбидов титана и карбоборидов $(\mathrm{Ti}, \mathrm{Cr})(\mathrm{C}, \mathrm{B})(\mathrm{cm}$. рис. 1б; $2 б$ и $3 б)$. 
Покрытие NiCrBSi по всей толщине (h 0,75 мм) характеризуется относительно небольшим разбросом значений микротвердости (рис. 4a). Это является следствием высокой дисперсности фаз в структуре данного покрытия (см. рис. $1 a$ и $3 a$ ). При добавлении 25 масс.\% карбида титана в порошок ПГ-СР2 существенно возрастает не только уровень, но и разброс значений микротвердости (рис. 4б) прежде всего с наличием в рассматриваемом композиционном покрытии $\mathrm{NiCrBSi}$ - TiC крупных частиц TiC с микротвердостью HV 25002900 (см. рис. 16 и 3б). Это отражается также в росте погрешности измерений микротвердости от \pm 10 ед. HV0,1 у покрытия NiCrBSi до \pm 60 ед. HV0,1 у композиционного покрытия $\mathrm{NiCrBSi}-\mathrm{TiC}$ (см. табл. 1).

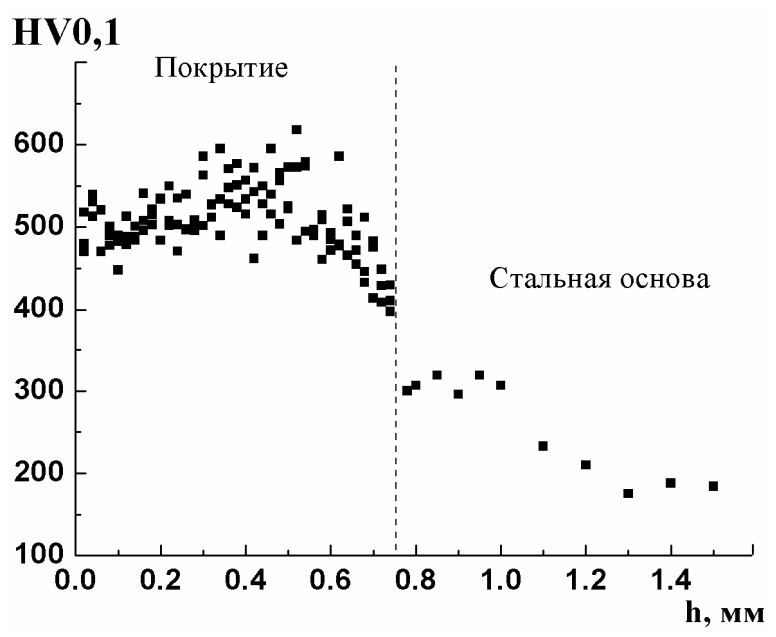

$a$

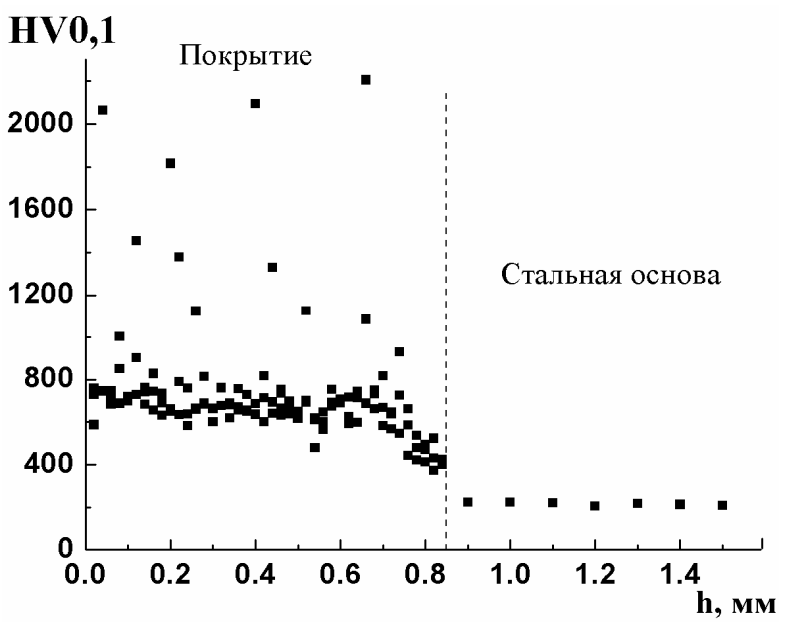

$\sigma$

Рис. 4. Изменение микротвердости (HV0,1) по толщине (h) покрытий $\mathrm{NiCrBSi}(a)$ и $\mathrm{NiCrBSi}-\mathrm{TiC}(б)$

Таблица 1 - Средняя микротвердость HV0,1 в слое толщиной 0,6 мм и трибологические характеристики* покрытий различного состава при испытании по закрепленному абразиву различных видов

\begin{tabular}{|c|c|c|c|c|c|c|c|}
\hline \multirow[b]{2}{*}{$\begin{array}{c}\text { Состав наплавляемого } \\
\text { порошка, \% масс. }\end{array}$} & \multirow[b]{2}{*}{ HV0,1 } & \multicolumn{3}{|c|}{ Корунд } & \multicolumn{3}{|c|}{ Карбид кремния } \\
\hline & & Ih, $10^{-5}$ & f & 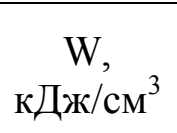 & Ih, $10^{-5}$ & $f$ & $\begin{array}{c}\mathrm{W}, \\
\text { кДж/см }\end{array}$ \\
\hline $100 \% \mathrm{NiCrBSi}$ & $520 \pm 10$ & 1,6 & 0,61 & 38 & 1,8 & 0,78 & 43 \\
\hline $75 \% \mathrm{NiCrBSi}+25 \% \mathrm{TiC}$ & $770 \pm 60$ & 0,4 & 0,46 & 115 & 1,0 & 0,69 & 69 \\
\hline
\end{tabular}

Из результатов испытаний на абразивное изнашивание исследуемых покрытий, представленных в табл. 1, видно, что формирование металломатричного композиционного покрытия обеспечивает рост трибологических свойств по сравнению со свойствами NiCrBSi покрытия при испытаниях по закрепленному абразиву различной твердости - корунду (твердостью $\sim$ HV 2000) и карбиду кремния (твердостью $\sim$ HV 3000): при добавке 25 масс.\% карбида титана снижается интенсивность изнашивания в 4,0 и 1,8 раза и коэффициент трения в 1,3 и 1,1 раза, а удельная работа изнашивания возрастает в 3,0 и 1,6 раза при испытаниях, соответственно, по корунду и карбиду кремния. Следовательно, рост трибологических свойств у композиционного покрытия в значительно большей мере проявляется при испытании по менее твердому абразиву корунду. Из данных табл. 1 следует также, что если у 
opten-aceEsS journal

$\mathrm{NiCrBSi} \mathrm{покрытия} \mathrm{при} \mathrm{испытаниях} \mathrm{по} \mathrm{обоим} \mathrm{абразивам} \mathrm{наблюдаются} \mathrm{близкие} \mathrm{уровни} \mathrm{интен-}$ сивности абразивного изнашивания $\mathrm{Ih}=(1,6-1,8) \cdot 10^{-5}$, то у композиционного покрытия при переходе к более твердому абразиву (от корунда и карбиду кремния) интенсивность абразивного изнашивания возрастает в 2,5 раза (от $\mathrm{Ih}=0,4 \cdot 10^{-5}$ до $\mathrm{Ih}=1,0 \cdot 10^{-5}$ ).

На рис. 5 и 6 приведены результаты исследования на сканирующем электронном микроскопе поверхностей изнашивания покрытий после испытаний по корунду и карбиду кремния.
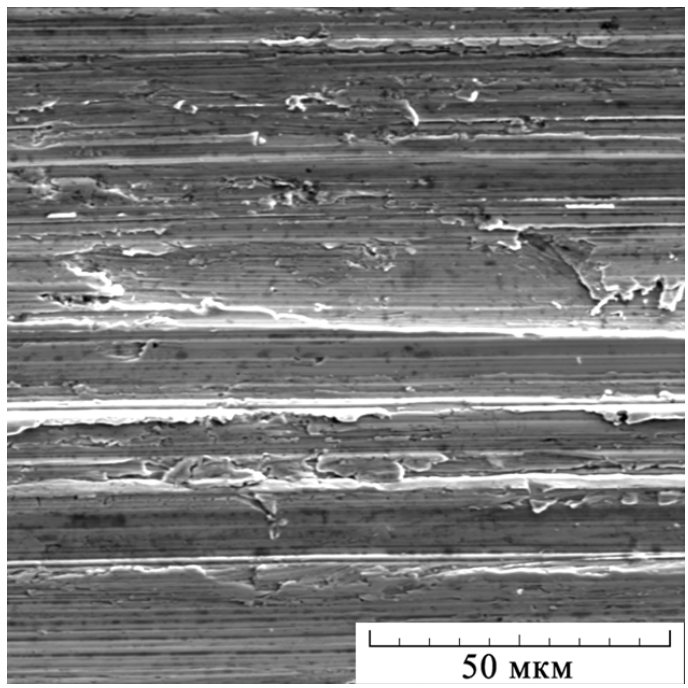

$a$

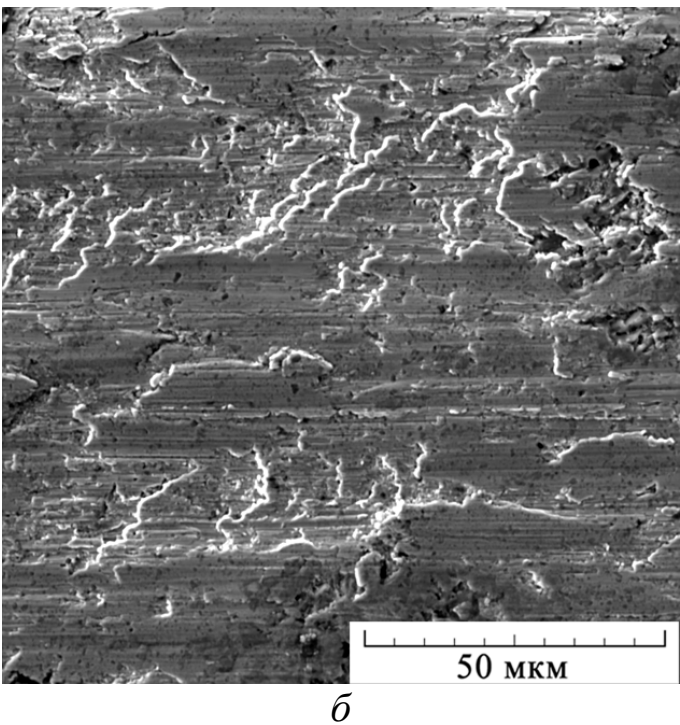

Рис. 5. Поверхности абразивного изнашивания после испытаний по корунду покрытий $\mathrm{NiCrBSi}(a)$ и $\mathrm{NiCrBSi}-\mathrm{TiC}(б)$
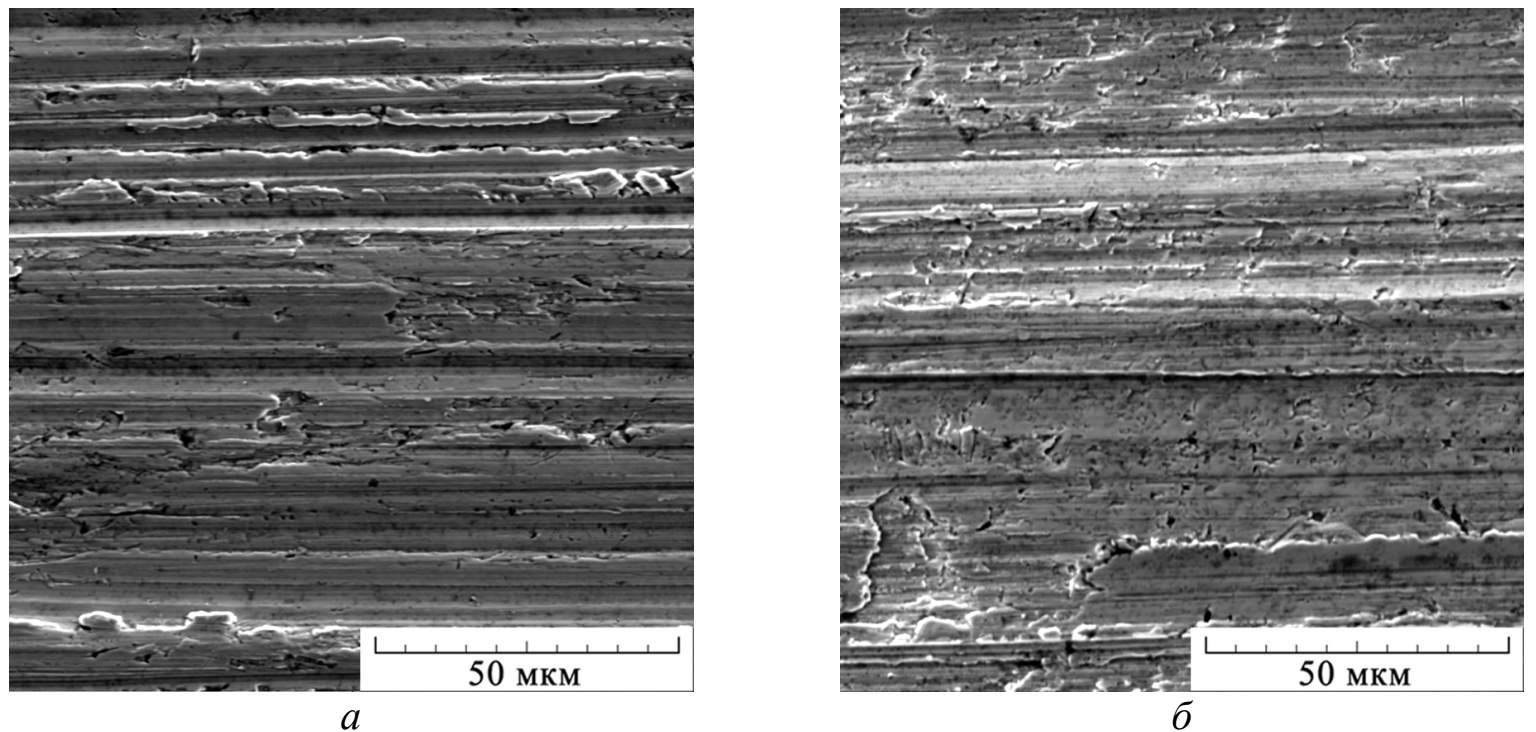

Рис. 6. Поверхности абразивного изнашивания после испытаний по карбиду кремния покрытий $\mathrm{NiCrBSi}(a)$ и $\mathrm{NiCrBSi}-\mathrm{TiC}(б)$

Видно, что изнашивание NiCrBSi покрытия в обоих случаях происходит по механизму микрорезания, развитие которого сопровождается возникновением на поверхностях образцов характерных продольных борозд с отвалами металла (рис. $5 a$ и $6 a$ ), а продукты изнашивания имеют преимущественно вид микростружек, образующихся в процессе одноактного отделения микрообъема металла под воздействием абразивного зерна [22, 31]. Основная упрочняющая фаза данного покрытия (карбид хрома $\mathrm{Cr}_{23} \mathrm{C}_{6}$ микротвердостью $\mathrm{HV}$ 1000-1150)

Makarov A. V. et al. / The tribological performances of a NiCrBSi - TiC laser-clad composite coating under abrasion and sliding friction. 
существенно уступает в твердости как корунду, так и карбиду кремния, и вследствие этого не препятствует активному развитию микрорезания [32]. Реализация одинакового механизма изнашивания (микрорезания) при испытании покрытия NiCrBSi по абразивам различной твердости объясняет отмеченные для этих случаев близкие уровни интенсивностей изнашивания (см. табл. 1).

После испытания композиционного покрытия $\mathrm{NiCrBSi}$ - TiC по менее твердому абразиву корунду на поверхности изнашивания (рис. 5 б) наблюдаются следы передеформирования металла, а также усталостные микротрещины, характерные для малоцикловой фрикционной усталости [33]. Однако почти отсутствуют связанные с отделением микростружек выраженные однонаправленные впадины (борозды) и выступы. Это указывает, что разрушение покрытия с $25 \%$ ТiC при испытании по корунду в значительной степени происходит по механизму пластического оттеснения (царапания) [32], который характеризуется существенно меньшей, чем механизм микрорезания, скоростью отделения продуктов изнашивания преимущественно в виде чешуек [22, 31].

В результате преобладания царапания при испытании по корунду у композиционного покрытия отмечается минимальная интенсивность изнашивания $\mathrm{Ih}=0,4 \cdot 10^{-5}$ (см. табл. 1). Это обусловлено наличием в структуре указанного покрытия частиц карбида TiC (см. рис. 16 и 3 б), значительно более крупных и твердых, чем карбид хрома $\mathrm{Cr}_{23} \mathrm{C}_{6}$, являющийся основной упрочняющей фазой покрытия $\mathrm{NiCrBSi}$ (см. рис. 1a). Крупные частицы TiC образуют в композиционном покрытии высокопрочный каркас и препятствуют реализации микрорезания, поскольку их твердость (HV 2500-2900) превышает твердость корунда ( HV 2000). Присутствующие в композиционном покрытии сложные карбобориды $(\mathrm{Ti}, \mathrm{Cr})(\mathrm{C}, \mathrm{B})$ (см. рис. 1 б; 2 б и 3 б), твердость которых близка или даже выше твердости корунда, также ограничивают развитие микрорезания на поверхности покрытия при воздействии абразивом корундом.

На поверхности изнашивания покрытия NiCrBSi - TiC после испытания по карбиду кремния присутствуют как следы микрорезания в виде борозд, так и выглаженные участки пластического деформирования и отдельные усталостные микротрещины (рис. 6 б). Это свидетельствует о смешанном механизме изнашивания (царапание + микрорезание) композиционного покрытия при испытании по наиболее твердому абразиву карбиду кремния. Твердость карбида кремния ( HV 3000) в данном случае не обеспечивает реализацию микрорезания только для наиболее прочных частиц карбида титана, имеющего твердость HV 2500-2900, поскольку микрорезание надежно развивается лишь при превышении твердости абразива над твердостью испытуемого материала более чем в 1,3-1,4 раза [32].

Результатом развития смешанного механизма изнашивания покрытия $\mathrm{NiCrBSi}-\mathrm{TiC}$ при испытании по карбиду кремния является достигаемый в этом случае уровень интенсивности абразивного изнашивания $\mathrm{Ih}=1,0 \cdot 10^{-5}$, занимающий, согласно данным табл. 1 , промежуточное положение между минимальным значением $\mathrm{Ih}=0,4 \cdot 10^{-5}$, характерным для преобладания механизма царапания при изнашивании по корунду покрытия с $25 \% \mathrm{TiC}$, и максимальными значениями $\mathrm{Ih}=(1,6-1,8) \cdot 10^{-5}$, наблюдаемыми при реализации механизма микрорезания в случаях изнашивания покрытия $\mathrm{NiCrBSi}$ по обоим видам абразивов $\left(\mathrm{Al}_{2} \mathrm{O}_{3}\right.$ и $\left.\mathrm{SiC}\right)$.

Ограничение процессов микрорезания, обусловленное наличием в композиционном покрытии высокопрочного каркаса из крупных частиц ТiC, не только эффективно снижает интенсивность изнашивания и повышает удельную работу изнашивания (т.е. для разрушения покрытия с 25 \% ТіС требуется совершение большей работы), но и способствует уменьшению коэффициента трения (см. табл. 1). Это, по-видимому, является следствием снижения механической составляющей коэффициента трения, связанной с сопротивлением механическому деформированию (пропахиванию) поверхностного слоя абразивными частицами.

В табл. 2 представлены результаты испытаний рассматриваемых покрытий в условиях сухого трения скольжения по пластине из высокопрочной штамповой стали Х12М. Из дан-

Makarov A. V. et al. / The tribological performances of a NiCrBSi - TiC laser-clad composite coating under abrasion and sliding friction. 
ных табл. 2 следует, что в условиях фрикционного нагружения введение в состав покрытия 25 масс. \% карбида титана обеспечивает снижение интенсивности изнашивания в 1,8 раза.

Таблица 2 - Интенсивность изнашивания Ih и коэффициент трения f покрытий различного состава при испытании на сухое трение скольжения по стальной пластине Х12M

\begin{tabular}{|l|c|c|}
\hline Состав наплавляемого порошка, \% масс. & $\mathrm{Ih}, 10^{-8}$ & $\mathrm{f}$ \\
\hline $100 \% \mathrm{NiCrBSi}$ & 6,0 & 0,40 \\
\hline $75 \% \mathrm{NiCrBSi}+25 \% \mathrm{TiC}$ & 3,4 & 0,62 \\
\hline
\end{tabular}

Наличие повышенного коэффициента трения $(\mathrm{f}=0,62)$ у композиционного покрытия является, очевидно, следствием влияния каркаса из крупных частиц карбида ТiC на молекулярную составляющую коэффициента трения, определяющее влияние на величину которой оказывают химический состав материалов пары трения и формирующиеся в зоне фрикционного контакта окислы [33].

Анализ электронно-микроскопических изображений поверхностей трения показывает, что процессы пластического оттеснения значительно более интенсивно развиваются на поверхности покрытия NiCrBSi (рис. 7 a), чем на поверхности покрытия NiCrBSi - TiC (рис. 7 б). Поверхность трения композиционного покрытия отличается наличием участков, отмеченных стрелками на рис. 7 б, в которых, согласно результатам поэлементного картирования с использованием микроанализаторов, содержится повышенная концентрация титана (рис. 8 a). Следовательно, рассматриваемые участки являются крупными частицами карбидами титана. Таким образом, несмотря на высокую хрупкость карбида титана и наличия в его частицах несплошностей (см. рис. 1 и и 3 б), в процессе трения не происходит полного выкрашивания высокопрочных крупных частиц карбида TiC (см. рис. 7 б). Указанные частицы формируют на поверхности трения композиционного покрытия $\mathrm{NiCrBSi}-\mathrm{TiC}$ высокопрочный износостойкий каркас (см. рис. 7 б и $8 a$ ), который препятствует развитию деформационных процессов при трении и таким образом снижает интенсивность полидеформационного (усталостно-адгезионного) механизма изнашивания $[33,34]$. Этим также достигаются условия для формирования на поверхности трения композиционного покрытия окислов, поскольку пластическая деформация в зоне фрикционного контакта приводит к разрушению устойчивых поверхностных пленок [34]. Возникающие окислы эффективно экранируют контактирующие поверхности, препятствуя их адгезионному взаимодействию и последующему изнашиванию $[35,36]$. Как показали результаты картирования (см. рис. 8), на участке поверхности трения $\mathrm{NiCrBSi}$ - TiC покрытия отмечаются повышенные концентрации железа и кислорода при почти полном отсутствии никеля (см. рис. 8 б; 8 в и 8 г). Это свидетельствует о том, что рассматриваемые окислы являются преимущественно оксидами железа. Таким образом, при испытаниях на трение скольжения без смазки на воздухе у композиционного покрытия $\mathrm{NiCrBSi} \mathrm{-} \mathrm{TiC} \mathrm{преобладает} \mathrm{нормальное} \mathrm{механохимическое} \mathrm{(окислительное)} \mathrm{изнашивание,}$ характеризующееся малой интенсивностью разрушения [35, 37].

Следовательно повышенная износостойкость композиционного покрытия в условиях сухого трения скольжения (см. табл. 2) обусловлена тем, что каркас из высокопрочных карбидов титана эффективно ограничивает и локализует процессы пластического оттеснения, приводящие к разрушению поверхностного слоя покрытий и препятствующие формированию на поверхности трения устойчивых окисных пленок. 
open-access jürnal
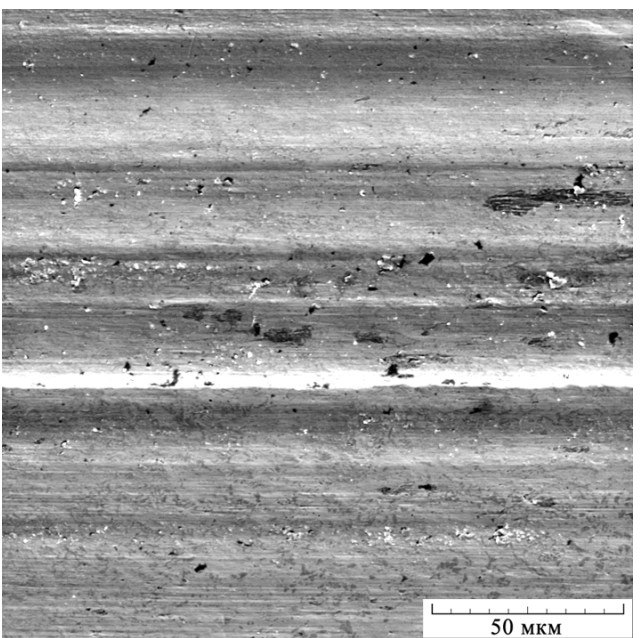

$a$

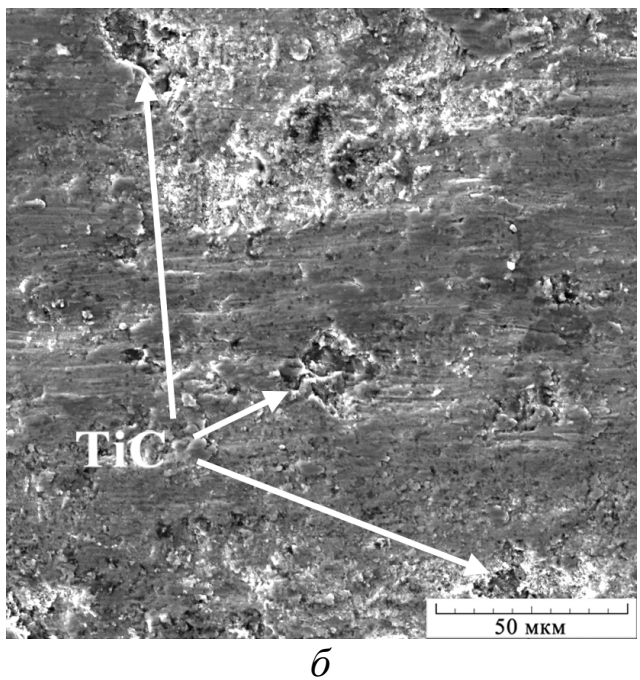

6

Рис. 7. Поверхности изнашивания после испытаний на трение скольжения без смазки по пластине из стали X12M покрытий $\mathrm{NiCrBSi}(a)$ и $\mathrm{NiCrBSi}-\mathrm{TiC}(\sigma, \varepsilon)$
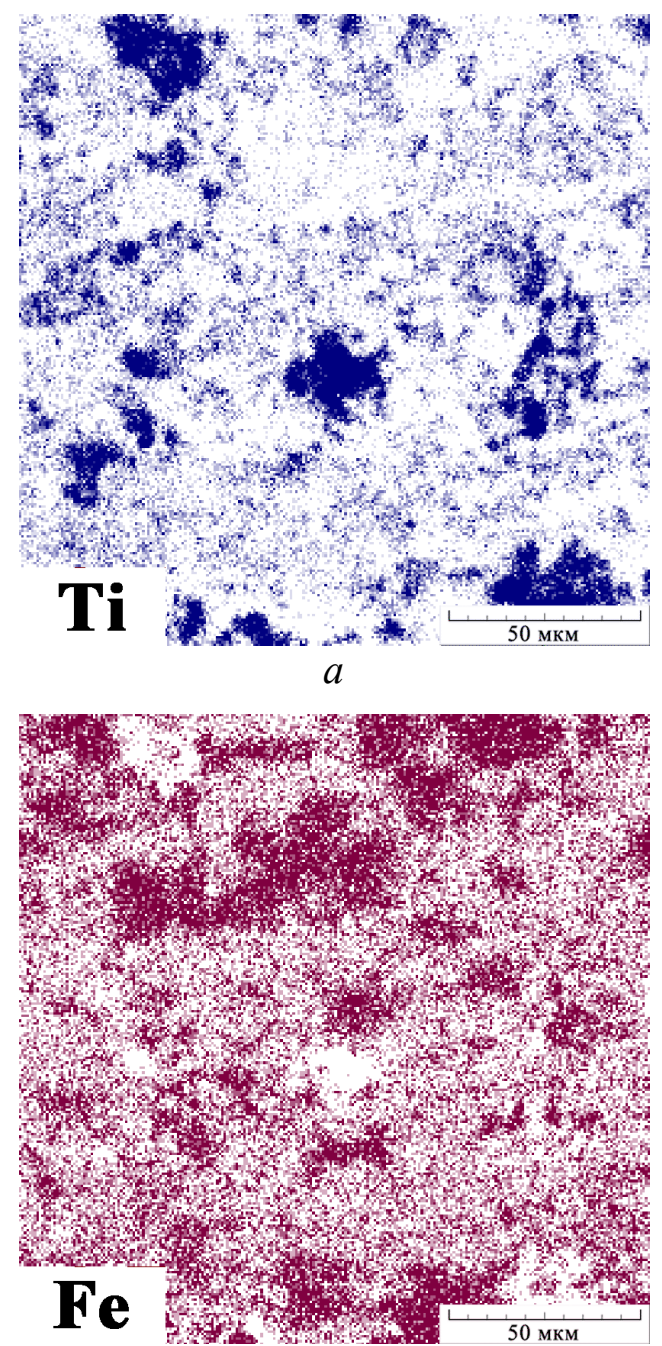

B

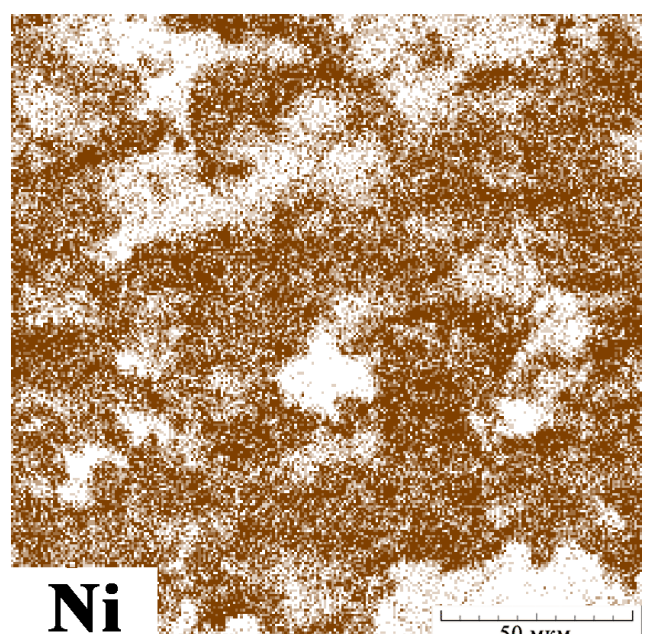

$\sigma$

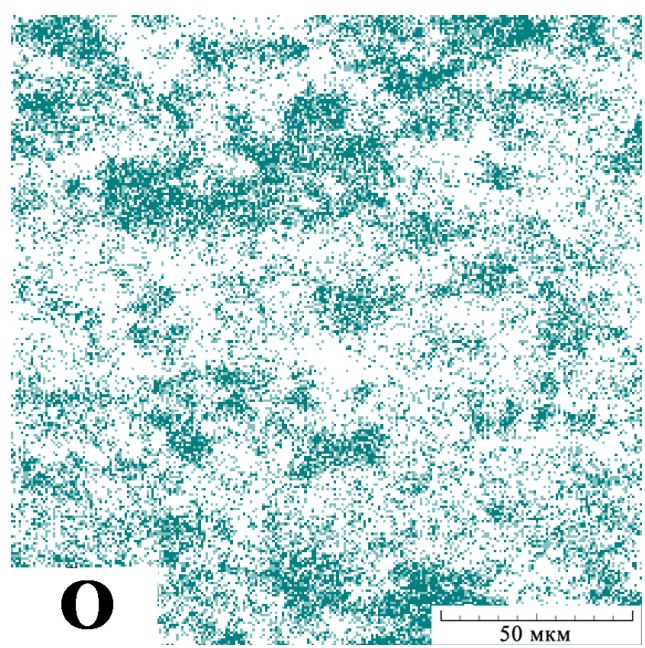

2

Рис. 8. Распределение элементов титана ( $a$ ), никеля (б), железа (в) и кислорода (2) на участке, изображенном на рис. 76 


\section{4. Заключение}

Сформированное на стальной поверхности методом газопорошковой лазерной наплавки композиционное покрытие состава 75 масс.\% NiCrBSi +25 масс.\% TiC содержит в структуре крупные включения первичных карбидов титана ТiC микротвердостью HV 2500-2900, что обеспечивает повышенную микротвердость и износостойкость в условиях абразивного воздействия и сухого трения скольжения по сравнению с характеристиками базового NiCrBSi покрытия с основной упрочняющей фазой $\mathrm{Cr}_{23} \mathrm{C}_{6}$, имеющей микротвердость HV 1000-1150.

Эффективность повышения износостойкости при формировании металломатричного композиционного $\mathrm{NiCrBSi}$ - TiC покрытия зависит от влияния высокопрочного каркаса из крупных карбидов ТiC на реализуемые в конкретных условиях фрикционного нагружения механизмы изнашивания.

В условиях изнашивания по закрепленному абразиву существенно большее снижение интенсивности изнашивания у композиционного покрытия наблюдается при испытании по корунду (в 4,0 раза), чем при испытании по карбиду кремния (в 1,8 раза). Это обусловлено более эффективным ограничением крупными карбидами ТіС процессов микрорезания при испытании по корунду твердостью HV 2000 (вплоть до смены основного механизма изнашивания от микрорезания к царапанию при переходе от базового покрытия NiCrBSi к покрытию $\mathrm{NiCrBSi}-\mathrm{TiC})$, чем при испытании по более твердому ( HV 3000) абразиву карбиду кремния, когда на поверхности композиционного покрытия развивается смешанный механизм изнашивания (царапание + микрорезание).

Повышенная (в 1,8 раза по сравнению с NiCrBSi покрытием) износостойкость композиционного покрытия NiCrBSi - TiC в условиях сухого трения скольжения на воздухе обусловлена эффективным ограничением и локализацией каркасом из высокопрочных карбидов титана процессов пластического оттеснения. В результате у композиционного покрытия $\mathrm{NiCrBSi}$ - TiC преобладает нормальное механохимическое (окислительное) изнашивание, характеризующееся меньшей интенсивностью разрушения по сравнению с полидеформационным механизмом изнашивания, который более интенсивно развивается на поверхности трения покрытия NiCrBSi.

Исследования проведены на оборудовании ЦКП «Пластометрия» ИМАШ УрО РАН.

\section{Литература:}

1. Курганова Ю. А., Колмаков. А. Г. Конструкционные металломатричные композиционные материалы: учебное пособие. - М. : Изд-во МГТУ им. Н. Э. Баумана, 2015. - 141 с.

2. Курганова Ю. А. Перспективы развития металломатричных композиционных материалов промышленного назначения // Сервис в России и за рубежом. -2012 . - Т. 30, № 3. C. 235-240.

3. Yan H., Zhang P., Yu Zh., Lu Q., Yang Sh., Li Ch. Microstructure and tribological properties of laser-clad $\mathrm{Ni}-\mathrm{Cr} / \mathrm{TiB}_{2}$ composite coatings on copper with the addition of $\mathrm{CaF}_{2} / /$ Surface and Coatings Technology. - 2012. - Vol. 206. - P. 4046-4053.

4. Nurminen J., Näkki J., Vuoristo P. Microstructure and properties of hard and wear resistant MMC coatings deposited by laser cladding // Int. Journal of Refractory Metals and Hard Materials. - 2009. - Vol. 27. - P. 472-478.

5. Anandkumar R., Almeida A., Vilar R. Wear behavior of Al-12Si/TiB 2 coatings produced by laser cladding // Surface and Coatings Technology. - 2011. - Vol. 205. - P. 3824-3832.

6. Morphology and characterization of laser clad composite $\mathrm{NiCrBSi}$-WC coatings on stainless steel / M. J. Tobar, C. Álvarez, J. M. Amado, G. Rodríguez, A. Yánez // Surface and Coatings Technology. - 2006. - Vol. 200. - P. 6313-6317. 
7. Weng F., Chen Ch., Yu H. Research status of laser cladding on titanium and its alloys: A review // Materials and Design. - 2014. - Vol. 58. - P. 412-425.

8. Влияние химического состава на трибологические свойства хромоникелевых покрытий, полученных методом газопорошковой лазерной наплавки / А. В. Макаров, Р. А. Саврай, А. Л. Осинцева, И. Ю. Малыгина // Известия Челябинского научного центра. - 2009. № 2 (44). - С. 28-33.

9. Влияние микроструктуры и фазового состава на трибологические свойства nicrbsi лазерных покрытий / Н. Н. Соболева, И. Ю. Малыгина, А. Л. Осинцева, Н. А. Поздеева // Известия Самарского научного центра Российской академии наук. - 2011. - Т. 13, № 4 (3). C. 869-873.

10. Tribological properties of TiC particles reinforced Ni-based alloy composite coatings / B. Cai, Y.-F. Tan, L. He, H. Tan, L. Gao // Transactions of Nonferrous Metals Society of China. 2013. - Vol. 13. - P. 1681-1688.

11. Influence of laser cladding process on the magnetic properties of $\mathrm{WC}-\mathrm{FeNiCr}$ metal-matrix composite coatings / J. Yang, F. Liu, X. Miao, F. Yang // Journal of Materials Processing Technology. - 2012. - Vol. 212. - P. 1862-1868.

12. Niranatlumpong P., Koiprasert H. Phase transformation of NiCrBSi-WC and NiBSi-WC arc sprayed coatings // Surface and Coatings Technology. - 2011. - Vol. 206. - P. 440-445.

13. Effects of WC-Ni content on microstructure and wear resistance of laser cladding Ni-based alloys coating / Ch. Guo, J. Chen, J. Zhou, J. Zhao, L. Wang, Y. Yu, H. Zhou // Surface and Coatings Technology. - 2012. - Vol. 206. - P. 2064-2071.

14. Liyanage T., Fisher G., Gerlich A. P. Microstructures and abrasive wear performance of PTAW deposited Ni-WC overlays using different Ni-alloy chemistries // Wear. - 2012. Vol. 274-275. - P. 345-354.

15. Effect of Laser Power on Microstructure and Wear Resistance of $\mathrm{WC}_{\mathrm{P}} / \mathrm{Ni}$ Cermet Coating / S.-H. Si, X.-M. Yuan, Y.-L. Liu, Y.-Z. He, Sh. Keesam // Journal of Iron and Steel Research, International. - 2006. - Vol. 13. - Iss. 3. - P. 74-78.

16. Welding processes for wear resistant overlays / P. F. Mendez, N. Barnes, K. Bell, S. D. Borle, S. S. Gajapathi, S. D. Guest, H. Izadi, A. K. Gol, G. Wood // Journal of Manufacturing Processes. - 2014. - Vol. 16. - P. 4-25.

17. High temperature wear of cermet particle reinforced NiCrBSi hardfacings / A. Zikin, M. Antonov, I. Hussainova, L. Katona, A. Gavrilovic' // Tribology International. - 2013. - Vol. 98. - P. 45-55.

18. Microstructure and dry sliding wear behavior of laser clad Ni-based alloy coating with the addition of SiC / Q. Li, G. M. Song, Y. Z. Zhang, T. C. Lei, W. Z. Chen // Wear. - 2003. Vol. 254. - Iss. 3-4. - P. 222-229.

19. Microstructure and wear resistance of TaC reinforced Ni-based coating by laser cladding / M.-J. Chao, W.-L. Wang, E.-J. Liang, D. Ouyang // Surface and Coatings Technology. - 2008. Vol. 202. - P. 1918-1922.

20. Characterisation of TiC-NiMo reinforced Ni-based hardfacing / A. Zikin, E. Badisch, I. Hussainova, C. Tomastik, H. Danninger // Surface and Coatings Technology. - 2013. - Vol. 236. - P. 36-44.

21. Microstructure and wear properties of TiC/FeCrBSi surface composite coating prepared by laser cladding / X. H. Wang, M. Zhang, X. M. Liu, S. Y. Qu, Z. D. Zou // Surface and Coatings Technology. - 2008. - Vol. 202. - P. 3600-3606.

22. Формирование композиционного покрытия $\mathrm{NiCrBSi}-\mathrm{TiC}$ с повышенной абразивной износостойкостью методом газопорошковой лазерной наплавки / A. В. Макаров, Н. Н. Соболева, И. Ю. Малыгина, А. Л. Осинцева // Упрочняющие технологии и покрытия. 2013. - №11 (107). - C. 38-44. 
23. Sun R. L., Lei Y. W., Niu W. Laser clad TiC reinforced NiCrBSi composite coatings on Ti-6Al-4V alloy using a $\mathrm{CW} \mathrm{CO}$ laser // Surface and Coatings Technology. - 2009. - Vol. 203. P. 1395-1399.

24. Numerical simulation of temperature distribution and $\mathrm{TiC}$ growth kinetics for high power laser clad TiC/NiCrBSiC composite coatings / Y. Lei, R. Sun, Y. Tang, W. Niu // Optics and Laser Technology. - 2012. - Vol. 44. - P. 1141-1147.

25. A new theoretical model for high power laser clad $\mathrm{TiC} / \mathrm{NiCrBSiC}$ composite coatings on Ti6Al4V alloys / Y. Lei, R. Sun, Y. Tang, W. Niu // Optics and Lasers in Engineering. - 2010. Vol. 48. - P. 899-905.

26. Cavitation erosion resistance of Ti6Al4V laser alloyed with TiC-reinforced dual phase intermetallic matrix composites / M. Duraiselvam, R. Galun, V. Wesling, B. L. Mordike, R. Reiter, J. Oligmüller, G. Buvanashekaran // Materials Science and Engineering A. - 2007. - Vol. 454-455. - P. 63-68.

27. Tribological properties and wear prediction model of TiC particles reinforced Ni-base alloy composite coatings / Y.-F. Tan, L. He, X.-L. Wang, X. Hong, W.-G. Wang // Transactions of Nonferrous Metals Society of China. - 2014. - Vol. 24. - P. 2566-2573.

28. Tribological properties of Ni-base alloy composite coating modified by both graphite and TiC particles / B. Cai, Y.-F. Tan, Y.-Q. Tu, X.-L. Wang, H. Tan // Transactions of Nonferrous Metals Society of China. - 2011. - Vol. 21. - P. 2426-2432.

29. Dawei Z., Li T., Lei T. C. Laser cladding of $\mathrm{Ni}-\mathrm{Cr}_{3} \mathrm{C}_{2} /(\mathrm{Ni}+\mathrm{Cr})$ composite coating // Surface and Coatings Technology. - 1988. - Vol. 110. - P. 81-85.

30. Вихретоковый контроль твердости, износостойкости и толщины покрытий, полученных методом газопорошковой лазерной наплавки / А. В. Макаров, Э. С. Горкунов, И. Ю. Малыгина, Л. Х. Коган, Р. А. Саврай, А. Л. Осинцева // Дефектоскопия. - 2009. - №11. - С. $68-78$.

31. Повышение износостойкости закаленной конструкционной стали наноструктурирующей фрикционной обработкой / А. В. Макаров, Н. А. Поздеева, Р. А. Саврай, А. С. Юровских, И. Ю. Малыгина // Трение и износ. - 2012. - Т. 33. - № 6. - С. 587-598.

32. Хрущов М. М., Бабичев М. А. Абразивное изнашивание. - М. : Наука, 1970. - 252 с.

33. Крагельский И. В., Добычин М. Н., Комбалов В. С. Основы расчетов на трение и износ. - М. : Машиностроение, 1977. - 526 с.

34. Крагельский И. В. Трение и износ. - М. : Машиностроение, 1968. -480 с.

35. Голего Н. Л. Схватывание в машинах и методы его устранения. - Киев : Техника, 1966. $-231 \mathrm{c}$.

36. Носовский И. Г. Влияние газовой среды на износ металлов. - Киев : Техника, 1968. $181 \mathrm{c}$.

37. Поверхностная прочность материалов при трении / Б. И. Костецкий, И. Г. Носовский, А. К. Караулов и др. - Киев : Техника, 1976. - 296 с. 